\title{
Building and Deepening a Comprehensive Strategy to Internationalise Romanian Higher Education
}

\author{
Hans de Wit and Laura C. Engel
}

Keywords Internationalisation - Higher education • Romania - Mobility • Curriculum

\section{Introduction}

Now more than ever, internationalisation of education has captured the attention of education policy-makers and practitioners at national and institutional levels. In the last few years, more countries have begun to develop national strategies for internationalisation of education (either at higher or secondary education levels), including in the United States (U.S.) (Department of Education 2012), Australia (Commonwealth of Australia 2013), Canada (Government of Canada 2012), and Ireland (Report of the High-Level Group on International Education to the Tánaiste and Minister for Education and Skills 2010), among others. At a regional level, the European Commission (2013) recently released a higher education communication, 'European higher education in the world', which encourages internationalisation as

\footnotetext{
H. de Wit $(\bowtie)$

Centre for Higher Education Internationalisation (CHEI), Università Cattolica del Sacro Cuore, Milan, Italy

e-mail: hans.dewit@unicatt.it

H. de Wit

Internationalisation Higher Education, Amsterdam University of Applied Sciences, Amsterdam, Netherlands

H. de Wit

Unit for Higher Education Internationalisation in the Developing World, Nelson Mandela Metropolitan University, Port Elizabeth, South Africa

L.C. Engel

International Education and International Affairs, The George Washington University, Washington, United States of America

e-mail: Lce@gwu.edu

(C) The Author(s) 2015

A. Curaj et al. (eds.), Higher Education Reforms in Romania,

DOI 10.1007/978-3-319-08054-3_10
} 
central to meeting Europe 2020 benchmarks and addressing broader global challenges facing the region. Further, higher education institutions are also developing strategies of internationalisation. For example, in a European University Association (2013) study of 175 higher education institutions across 38 European countries, $99 \%$ responded that their institution had a strategy in place, was in the process of developing one, or had considered internationalisation in other institutional strategies. The International Association of Universities (IAU) (2010) survey on internationalisation of higher education showed that $89 \%$ of institutions worldwide indicate that internationalisation is part of their institutional mission statement, which is an increase of $78 \%$ compared to the survey conducted 3 years before (Green et al. 2012, p. 440).

Beyond institutional and national strategies, there is also a growth in global student mobility and increased competition in attracting international students. For example, from 2000 to 2010 , the number of globally mobile students grew from 2.1 million to 4.1 million, an annual increase of $7.2 \%$ (OECD 2012; UEFISCDI 2013). The majority of these students $(77 \%)$ choose to study in an Organisation for Economic Co-operation and Development (OECD) country, with the U.S., U.K., Australia and Canada topping the list of host countries (OECD 2012). Despite this trend, there is increased competition for international students as regions, including Latin America and the Caribbean, Oceania and Asia, become increasingly attractive destinations. In the last decade, the dominance of the three leading destinations has remained relatively steady (OECD 2012). In 2000, $39 \%$ of globally mobile students were enrolled either in the U.S. (23\%), U.K. (11\%), or Australia (5\%). This aggregate share declined slightly to $37 \%$ in 2010 , with the U.S. hosting $17 \%$, U.K. $13 \%$, and Australia $7 \%$. The other two leading nations for a long time, Germany and France, have stayed also in the top five, although they differ in several ways from the other top destinations: first of all by their languages, which is not English, the dominant global language in education currently; secondly by their tuition fees, which are much lower than in the other three countries, and thirdly - in particular in the case of France - by the background of their students, which is more diverse and more related to this country's historical ties, and cultural and linguistic area of influence (Choudaha and de Wit forthcoming).

Although it represents less than a tenth of the world's total population, Europe is and has been doing remarkably well in attracting degree-seeking foreign students. Over the last 10 years, it has in fact been the most popular continent for study abroad, receiving more than half of all students who studied towards a degree outside their country of origin. In contrast to other major study destinations, like the U.S.-whose 'market share' has continuously dropped after 2001-Europe has managed to preserve its position on the global education market, despite growing competition from non-traditional study destinations like China, India or Japan. In 2006/07, 1.5 million foreign full-degree students studied in 32 European countries - an all-time high, corresponding to $6.9 \%$ of all students enrolled in this region of the world and $50.9 \%$ of the total number of foreign students worldwide (Teichler et al. 2011). The number of foreign students in Europe has unquestionably gone through a marked increase from 1998/99 levels, when the number of foreign 
nationality students enrolled in Europe stood at only 827,000. Equally interesting, the number of foreign students in Europe increased at a much faster pace than the total number of students pursuing higher education studies in this region-which could point to Europe's increased attractiveness as a study destination, and also to a declining population of young people (Teichler et al. 2011). The European Commission, in its 2011 document 'Supporting growth and jobs - an agenda for the modernisation of Europe's higher education systems' concludes for the future: "Attracting the best students, academics and researchers from outside the EU and developing new forms of cross-border cooperation are key drivers of quality" (p. 6) and intends to "promote the EU as a study and research destination for top talent from around the world" (p. 14).

In spite of the increase in rhetoric of internationalisation and the growth in global student mobility, the concrete aims and actions related to internationalisation taken by higher education institutions vary. Against a framework of literature related to approaches and aims of internationalisation of education, this chapter explores some of these varying institutional practices of internationalisation within the national context of Romania. One of the deepest forms of internationalisation is a process approach (de Wit 2002; Knight 1999), in which institutions engage in a comprehensive strategy of infusing international perspectives into all aspects of teaching and learning. Yet, from case studies of five Romanian higher education institutions, the predominant vision for internationalisation was most often fairly strictly linked with mobility, specifically the increase in numbers of incoming and outgoing students and staff, primarily credit mobility within European programmes. And the instruments to stimulate this type of mobility were primarily the increase of bilateral agreements and of courses offered in English.

While significant, this form of internationalisation alone (fitting in the category of 'internationalisation abroad' according to the distinction in two components of internationalisation by Knight 2008) is not likely to lead to the development of global competence and mind-set for the majority of Romanian students, nor assist universities in creating a comprehensive internationalisation strategy with an equally strong focus on the other component, 'internationalisation at home'. Knight (2008) describes these two forms of internationalisation of education as inward and outward. Internationalization at home (inward) signifies a set of strategies and approaches to develop activities that help students' international understanding and intercultural skills, whereas internationalization abroad (outward) signifies cross-border mobility of students, teachers, scholars, programs, courses, curriculum and projects. These two components are not mutually exclusive but together encompass the broad scope of internationalisation of higher education in the current era.

Not only in Romania, but quite generally around the world, the focus in internationalisation of higher education is more on the 'abroad' component than on the 'at home' component. For instance, a survey of 38 European countries showed that for 175 higher education institutions, the number one goal for internationalisation was attracting international students (European University Association 2013). Although mobility is of course significant, it is not sufficient alone to meet the broader stated goals of developing global competence or mind-set. It is becoming 
more manifest than the abroad dimension of internationalisation, although in absolute numbers impressive, in percentages only reaches a small number of students and scholars and by that is both elitist and in its impact, limited. Also, several authors (for instance Leask 2005; Otten 2003; Teekens 2003, among others) consider it a misconception (de Wit 2012) that students acquire global or intercultural competences automatically by studying abroad. To realize a goal of more globally competent students and staff, mobility may not be the strategy with the greatest impact. Rather, internationalisation of the curriculum and the teaching and learning process is a more appropriate strategy, in which the outward dimension has to be integrated.

\section{Approaches and Rationales for Internationalization}

With globalisation, the world has become more interconnected, easing the flow of ideas, capital, and people across borders. Spring (2008) argued that globalisation of education referred to the ideas, decisions, institutions and organizations, and policy formation processes occurring at a global scale, which are understood to be affecting local, sub-national, national, and supra-national education systems, informing ideas and ideologies about education. One of the policy and institutional responses to these broader global processes is internationalisation of education, which Knight (2008) defines as "the process of integrating an international, intercultural, and global dimension into higher education's major functions and delivery modes at both the institutional and national levels" (p. ix). One of the central objectives of internationalisation strategies in education is to build a set of attitudes, beliefs, skills, and dispositions of individuals so that they are able to engage with their local and national communities, as well as the broader global world.

Within the academic literature, there has been growing attention to internationalisation of education. A broad search of literature related to 'internationalization' and 'education', on the JSTOR database reveals that there were 6,940 articles, books and pamphlets published from 1993 to 2013. On the ERIC database, a similar search shows the growth in academic literature from 282 articles in the 10 year period from 1992 to 2002 and 703 articles from 2003 to 2013. In addition to the academic literature, there is a growth in internationalisation of education as a profession. As de Wit and Urias (2012) observe, "The study of the internationalization of higher education has developed rapidly over the past two decades" (p. 101) and "one can see an increase in students and practitioners who consider international education a specialized career and look for master's and doctoral programs, as well as professional training modules" (p. 109).

Within the body of literature on internationalisation of higher education, there are a variety of rationales among both policy-makers and practitioners in favour of internationalisation. de Wit (2002) categorized these as political, economic, social/ cultural, and academic. An economic rationale may highlight skills and competencies necessary for individual citizens to be successful within the global economy, 
or highlight internationalisation as key to the long term economic success of a country, whereas a political rationale may emphasize the need for diplomacy and cross-cultural exchange, or see internationalisation as an important component of national security and/or capacity building. Social/cultural rationales highlight either the personal development dimension of higher education or the role of higher education in civic and cultural engagement. Academic rationales are strongly related to the status and branding of institutions and systems of higher education, the link to international standards and the extension of the horizon of research and/ or education.

Often there is a blend of multiple rationales within strategies of internationalisation. For example, the U.S. Department of Education's (2012) international education strategy appears to be underscored by several of the rationales described above, with its emphasis on internationalisation as central to economic prosperity and jobs, global challenges, national security and diplomacy, and the diversity within U.S. society (for further analysis of these rationales underlying the U.S. internationalisation strategy, see Engel et al. 2013). The recent communication of the European Commission (2013) in its three key pillars, Mobility and the recognition which this requires; Internationalisation at home, including digital learning; and Strategic cooperation and partnership, including capacity, also combines different rationales. These three priorities are in and of themselves not new; however, they do provide the rationales for, as well as reflection in their comprehensiveness and recognition at the EU level, a foundation to enhance the internationalisation of the European higher education sector in the coming years.

These distinct rationales tend to guide the different approaches to internationalisation. Knight (1999) distinguishes between four main approaches to internationalisation of education. These are activity, competency, ethos, and process approaches. The activity approach includes actions related to the exchange of students or staff and technical assistance. It often focuses more narrowly on one or more specific activities or programmes, which can be isolated from other areas of education and specific to only a sub-set of students or staff. Often, the most popular form of the activity approach is mobility related, with an objective to increase the numbers of incoming or outgoing students. The competency approach highlights the development of competencies, both at the level of students and staff. Quite distinct from the skills approach is the ethos or values-based approach, which includes developing a culture to support internationalisation. Lastly, the process approach is arguably the deepest form, as it focuses not on distinct or isolated activities, but on integrating an international dimension into research and service through activities, policies, and procedures (Knight 1999). It is considered the deepest form of internationalisation, as it has the potential to involve aspects of the other three approaches (activities, competencies, ethos), and be infused into the context and culture of an education system or institution. For instance, mobility (or the outward dimension) is integrated into a broader teaching and learning process. In this way, rather than affecting only a small proportion of students and staff through a singular, and at times 'add on' approach, internationalisation as a process can enhance global mind-set and competence, as well as deepen the experience of internationalisation outside of a 
singular abroad opportunity. Moreover, the process approach may be the most useful approach for assisting institutions in developing a comprehensive internationalisation strategy. Currently, it is also referred to as comprehensive internationalisation (Hudzik 2011).

We argue that internationalisation becomes deepest and most extensive when it is infused throughout the teaching and learning process, enriching global competences and perspectives for the majority of students and staff, not only a select few engaged in a single activity. According to Boix Mansilla and Jackson (2011), global competence is "the capacity and disposition to understand and act on issues of global significance" (p. xi). In a framework developed by the Asia Society, the four dimensions of education for global competence include student investigations of the world, recognition of students' own perspectives and others different from their own, the ability to communicate ideas to diverse audiences, and taking action based on knowledge and perspectives gained (Boix Mansilla and Jackson 2011).

Infused within these four dimensions is what Rizvi (2007) had earlier referred to as global-local reflexivity, which aims to build a deep and extensive form of global competence within the home campus. In an approach that aims to build global-local reflexivity, 'the global' is not abstract or separate from the everyday life of the campus or school, something that the university either sends its students and staff to go and 'get', or receives students and staff from. Rather, it views 'the global' as part and parcel of the lives of students, staff, and the university. It is not primarily "concerned with imparting knowledge and developing attitudes and skills for understanding other cultures per se" (Rizvi 2007, p. 6). Rather, a reflexive approach helps students to explore "the ways in which global processes are creating conditions of economic and cultural exchange that are transforming our identities and communities; and that, reflexively, we may be contributing to the production and reproduction of those conditions, through our uncritical acceptance of the dominant ways of thinking about global interconnectivity" (p. 6). It places students, staff and individuals at the center of global processes. Internationalisation then is about asking students to understand and ask critical questions about their place in the world and the ways in which they are actors in global processes, and how in turn they are affected by broader global processes.

This approach to internationalisation requires considerable strategic thought (the what, how, why) and a deepening of internationalisation (not simply a 'more is better' approach limited to cross-border mobility). Hudzik (2011) defines comprehensive internationalisation as both a commitment and action "to infuse international and comparative perspectives throughout the teaching, research, and service missions of higher education...it is an institutional imperative, not just a desirable possibility" (p. 6). Although the process approach is the deepest form of internationalisation, in most systems around the world, both at a national and institutional level, the activity approach often is the most common (de Wit 2013), as also shown in the Romanian case. 


\section{Methodology}

The chapter draws on data and findings from the research project, Higher education evidence-based policy making: a necessary premise for progress in Romania', carried out by The Executive Agency for Higher Education, Research, Development and Innovation Funding (UEFISCDI). As part of the project, there was a focus on two central dimensions (equity and internationalization). The project team included members of UEFISCDI, the International Association of Universities (IAU), and a team of national and international experts. Throughout 2013, the authors participated in the project as international experts on the project dimension of internationalisation. In that role, we participated in mutual learning workshops with the UEFCISDI/IAU team members and other international and national experts, as well as in the project design. Either one or both of us also participated in each of the five institutional site visits to the universities participating in the project, and were each involved with analysis of the project findings.

The project drew on institutional analysis based on the 'Internationalization strategies advisory service' (ISAS) of the IAU (http://www.iau-aiu.net/content/isas). The ISAS approach is structured around analysis of institutional strategies of internationalisation through a process of self-study and peer learning. Universities were invited on a voluntary basis to take part in the project. Five universities participated, including both public and private universities from different areas of Romania, providing an array of institutional practices in internationalisation. The universities first completed the Internationalisation Self-Study according to a Guide, adapted by the project team from the ISAS framework. Each self-study report was then analysed by the project team. From May-September, 2013, site visits to each of the participating institutions was conducted by members of the project team and national and international experts. The institutional visit was carried out over the course of one day, and aimed to assess both the policies and practices of the institutions with respect to internationalisation of education, as well as gather the perspectives, experiences, and opinions of university representatives about national and institutional level internationalisation. During each visit, interviews were conducted with university representatives, including high level university administrators, deans, faculty, staff, and students.

The project report (UEFISCDI 2013) provides the full findings related both to internationalisation of higher education at a national and institutional level, and the policy recommendations emerging from the project. In this chapter, we are drawing on select findings related to two key dimensions of internationalisation of higher education at the national and institutional level as described above: the importance of the European context and the lack of comprehensive strategies for internationalisation. Related issues are the focus on internationalisation abroad, although rather marginal in performance, and the lack of a strategy to enhance internationalisation at home, although in words it is embraced as important. 


\section{Internationalisation of Higher Education in Romania Within the European Context}

With the Bologna Declaration in 1999, governments of 47 countries made a commitment to harmonize their higher education systems through a range of actions, including those specifically related to internationalisation of higher education. The broader goals were to create a more competitive and attractive European higher education system and to enhance cross-border student mobility and employability. Ten years later in 2009 in Leuven/Louvain-la-Neuve and in 2012 in Bucharest, Ministers emphasised the importance of quality higher education to build lifelong learning and employability (UEFISCDI 2013). For the immediate 2012-2015 timeframe, the 47 countries of the European Higher Education Area prioritise mobility as a way to foster quality higher education for all and strengthen graduates' employability. In 2012, the Mobility Strategy 2020 for the European Higher Education Area was launched (European Higher Education Area 2012).

While mobility is one of the central aims of these European initiatives, recent European Union developments have emphasized other dimensions of internationalisation. In 2013, the European Commission released the Communication, 'European higher education in the world', which was a response to the Council conclusions (2010) on the internationalisation of higher education. The 2013 Communication prioritizes internationalisation as at the core of advancing the Europe 2020 objectives. As mentioned above, it encourages both member states and individual higher education institutions to consider three main priorities in their efforts to develop more comprehensive approaches to internationalisation. These include advancing international student and staff mobility, internationalisation of home through curricula and digital learning, and strategic cooperation and academic partnerships (European Commission 2013).

Strongly driven by the European initiatives and programmes in the s, both at a national level and within individual higher education institutions, Romania has placed an increased focus on internationalisation of higher education. Beginning in the 1990s, a vision for an internationalised higher education system in Romania began to develop. Before this point, there was, under the Ceausescu regime, a focus on growing the enrolments of foreign students through provision of Romanian language courses, specialized university regulations, or mechanisms of financial assistance (UEFISCDI 2013). As Romania joined Socrates and Erasmus in the 1990s, the influx of international students began to be diversified. During this same period, there were Ministry of Education programs offered in foreign languages (UEFISCDI 2013). As a result, the number of foreign degree seeking students and credit seeking students steadily grew. In 2002-2003, the number of foreign degree students reached 9,830 (1.69\% of total students) and the total number of credit seeking students in 2009 was 15,391 (UEFISCDI 2013). Though comprehensive data are difficult to access, as there are no centralized data collection mechanisms, there are about four times more outgoing Erasmus students than incoming Erasmus students, and about 3.5 times more outgoing students (total) from incoming students (UEFISCDI 2013). 
New developments in the internationalisation of Romanian higher education include cross-border developments. According to the 2013-2016 Romanian Government Program on Education, internationalisation of education is important "to continue to strengthen international bilateral and multilateral partnerships, foster exchanges of students, teachers, in the existing programs and developing new ways of international cooperation" (UEFISCDI 2013). In the past 2 years, two universities (Maritime University of Constanta and "Dunarea de Jos" University of Galati) have opened branch campuses in other countries, including in Kazakstan and the Republic of Moldova. There is also a well-established pattern of cross-border partnerships between Romanian and German universities, with approximately 357 partnerships on record, and with Hungary, Serbia, Bulgaria, Republic of Moldova and Ukraine through the Phare Programme (UEFISCDI 2013).

Although one can observe a gradual increase over the past few years in degree and credit mobility and cross-border delivery of programmes, both in absolute numbers and as a percentage of all students and programmes, Romania is underperforming compared to most other European countries. Even if we compare Romania to neighbouring countries like Bulgaria (3.5\%), Hungary (3.5\%) and Slovenia $(1.3 \%)$, Romania has relatively low numbers of incoming students as a percentage of the total student population. Out of 33 European countries, only Lithuania, Latvia, Poland, Slovakia and Turkey have lower percentages than the $1.3 \%$ for Romania. The same can be said of the ratio of students enrolled abroad to nationals enrolled at home, where Romania with 0.027 is among the ten lower performing countries, although that also applies to countries like U.K., Spain and Italy (de Wit et al. 2012, p. 5-6). In the context of the new policy of the Commission, the rather exclusive focus on but limited success in the first pillar (mobility), requires a rethinking of the national and institutional approach to internationalisation.

\section{Internationalisation Strategies of Romanian Higher Education Institutions}

As argued by Hudzik (2011), comprehensive internationalisation at an institutional level requires both institutional strategy and action in order to infuse international perspectives into all aspects of university life. In the European University Association (2013) study of 175 institutions in 38 European countries, $56 \%$ indicated that the institution either has a strategy of internationalisation in place, $30 \%$ considered internationalisation in other institutional strategies, and $13 \%$ were planning to develop an internationalisation strategy. The survey results also showed that participants view strategies as having a significant impact on new overseas partnerships, increased outward student mobility, increased incoming international students, numbers of English courses, and initiating joint/double degrees. In Romania, of the five institutional cases in the study, only one had a concrete written strategic document. However, all of the institutional representatives indicated that they were in the process of developing an institutional strategy for internationalisation, first 
exploring examples of internationalisation strategies used in the U.S., Australia and other European countries.

As representatives of the five institutions discussed their goals for internationalisation, it was evident that their rationales varied widely. Among the concrete goals articulated were the development of higher quality foreign language degree programmes (in French or primarily in English); the development of joint degree programmes; enhancing the prestige of the institution through cross-national research projects; increased cooperative partnerships and networks with universities overseas; increasing more student and staff mobility; enhancing support for incoming and outgoing students; and the promotion of Romanian language and culture abroad (UEFISCDI 2013). These are a diverse set of activities, which were often not linked or integrated into a comprehensive internationalisation strategy.

Although representatives articulated an array of different goals, in general, Romanian higher education institutions seemed most concerned with outward and inward mobility of students and staff, as well as partnerships and cross-border relationships. This concern with mobility and partnerships dictated the institutional approaches to internationalisation which the institutions adopted. For example, one of the case universities in the study had recently signed a contract with an African country to train 200 of its students at the university in Romania, a program which the Romanian institutional representatives aimed to repeat annually. The opportunity for cross-border partnership of this kind appears to have great potential to assist in the institutional internationalisation. Yet, the focus appeared largely on the institutional gains from inward student mobility, as well as limited cultural and institutional orientations of foreign students to Romanian life. Absent were any initiatives or plans to grow the global competence of Romanian students through the opportunity, such as through planned intercultural learning activities between Romanian and foreign students, or to benefit from incoming international students in internationalising the curriculum.

With the dominant focus on mobility, as well as partnerships and cross-border relationships, there is little evidence specific to how higher education institutions in Romania have developed and implemented strategies related to internationalisation at home. Certainly, Romanian higher education institutions' policies and curriculum have been impacted by the use of European Credit Transfer System, the restructuring of Romanian higher education to comply with the three Bologna-cycles, and broader quality assurance frameworks within the European Higher Education Area. Yet, despite these changes, there is no evidence of any Romanian institution developing a vision or strategy specifically related to internationalisation at home. And where such an approach exists it is primarily focussed on the development of courses and programmes in other languages and improvement of the foreign language skills of staff and students. Although there are some valuable examples of courses and programmes in other foreign languages (French, Italian and German) the primary interest appears to be in developing courses and programmes in English (and related recruitment of international students from the non-European, mainly Asian, market) and improvement of English language skills. One can question the impact of such an approach, given that it prepares for opportunities to and assumes 
success in competing effectively on the global/international student market, and ignores the opportunities in neighbouring countries and markets closer to the Romanian language.

\section{Concluding Remarks}

In this chapter we have placed the development of internationalisation of Romanian higher education in the context of the conceptual evolution of internationalisation, in particular the trend towards a more comprehensive strategy and a greater focus within such a comprehensive strategy on the 'at home' component of internationalisation. On the basis of the project, 'Higher education evidence-based policy making: a necessary premise for progress in Romania', carried out by The Executive Agency for Higher Education, Research, Development and Innovation Funding (UEFISCDI 2013) and assessment of the internationalisation policies of the five institutions of higher education within that project, we have identified some key trends and challenges for Romanian higher education in its efforts to become both more European and international. We observe that the European Union policies and programmes are driving the agenda, but also notice a lack of comprehensive strategies for internationalisation at the national and institutional level. We also observe a rather exclusive focus on internationalisation abroad, although the impact of that approach is relatively marginal, and we have identified a lack of a strategy to enhance internationalisation at home, although in theory, it is embraced as important by Romanian higher education institutional representatives.

Against a body of literature focused on the different forms of internationalisation, Romanian institutions remain focused on the activity approach, promoting the mobility of students, staff, and international students. Mobility in and of itself is an important component of internationalisation; however, in an isolated form, not integrated in the curriculum, it is not sufficient or effective. It is not part of a comprehensive strategy, often regarded within a 'more is better' framework, and is not seen to be linked to the overall quality of the education system.

To deepen internationalisation at an institutional level for the majority of higher education student populations, institutions require a more comprehensive approach, which entails:

(a) Development of skills, competences, attitudes, and values

(b) A culture to support international/intercultural perspectives

(c) Attention to the link between internationalisation and overall educational quality

(d) Integration of reflexivity into everyday school life

(e) Greater access of all students to internationalisation.

By furthering these elements, it is possible that internationalisation can further both the goals of educational quality and educational equity, rather than remain a limited opportunity only for a select group of students within an institution. 
Internationalisation is not an aim in and of itself; it is a mechanism for improving the overall quality of education (de Wit 2011, 2013; Qiang 2013). Institutions are required to tap into all of the different policy levers of internationalisation, not simply growing mobility and partnerships and/or teaching in English. On the one hand, this might help higher education institutions work toward their wider goals of enhancing quality of teaching, learning, and student services. On the other hand, it requires a more substantial and strategic initiative, not only toward internationalisation through programming, but a deeper internationalisation infused throughout many dimensions of the institution.

The issues related to internationalisation of higher education in Romania that we have highlighted in the chapter are also reflected in internationalisation trends in countries around the world. Indeed, much can be learned from the Romanian case. Despite the increase in strategies, mission statements and institutional rhetorical commitments to internationalisation, mobility (as part of the activity approach) often remains the leading practice prioritized at national and institutional levels in countries around the world. Despite the growth in global student mobility and the changing patterns of student flows, the vast majority of students around the world do not and will not study abroad. Those who do are typically among the more privileged who can afford to pursue a study abroad opportunity. Moreover, of those who do study abroad, roughly $77 \%$ choose to study abroad in an OECD country (OECD 2012), and in Europe, within Europe.

Arguably, the globalized world requires students to have expanded and deeper global competence, which includes the ability to communicate with others from different cultural backgrounds and the ability to connect and think reflexively about global influences on local and national communities. This requires a more expansive form of global competence for all students, which can only be achieved in the context of more comprehensive internationalisation at home strategies. Of course, foreign languages and mobility experiences are significant. However, alone they will not yield the expansion of global competence for all students.

Open Access This chapter is distributed under the terms of the Creative Commons Attribution Noncommercial License, which permits any noncommercial use, distribution, and reproduction in any medium, provided the original author(s) and source are credited.

\section{References}

Boix Mansilla, V., \& Jackson, A. (2011). Educating for global competence: Preparing our youth to engage the world. New York: Asia Society and Council of Chief State School Officers.

Choudaha, R., \& de Wit, H. (forthcoming) Challenges and opportunities for global student mobility in the future: A comparative and critical analysis. In B. Streitweiser (Ed.), Internationalization of higher education and global mobility, Oxford: Oxford Studies in Comparative Education Series, Symposium Books.

Commonwealth of Australia. (2013). Australia — educating globally: Advice from the International Education Advisory Council, Available online: http://aei.gov.au/IEAC2/theCouncilsReport/ Documents/Australia\%20-\%20Educating\%20Globally\%20FINAL\%20REPORT.pdf. 
de Wit, H. (2002). Internationalization of higher education in the United States of America and Europe. A historical, comparative, and conceptual analysis. Greenwood, USA.

de Wit, H. (2011). Trends, issues and challenges in internationalisation of higher education. Amsterdam: CAREM.

de Wit, H. (2012). Internationalisation of higher education: Nine misconceptions. In J. Beelen \& H. de Wit (Eds.), Internationalisation revisited: New dimensions in the internationalisation of higher education (pp. 5-8). Amsterdam: CAREM.

de Wit, H., Ferencz, I, \& Rumbley, L. E. (2012). International student mobility. Perspectives: Policy and practice in higher education, DOI: 10.1080/136033108.2012.679752.

de Wit, H., \& Urias, D. (2012). An overview and analysis of international education research, Training and resources. In D. D. Deardorff, H. de Wit, J. D. Heyl, \& T. Adams (Eds.), The SAGE handbook of international higher education (pp. 101-109). Thousand Oaks, CA: Sage Publications.

de Wit, H. (2013). Internationalisation of higher education: An introduction on the why, how and what. In H. De Wit (Ed.), An introduction into higher education internationalisation. Università Cattolica University Press Vita e Pensiero, Centre for Higher Education Internationalisation (CHEI), UCSC, Milan.

Department of Education. (2012). Succeeding globally through international education and engagement. Washington, DC: U.S. Department of Education, Available online: http://www2. ed.gov/about/inits/ed/internationaled/international-strategy-2012-16.pdf.

Engel, L. C., Conners, C., \& Siczek, M. (2013). Educating for global competence in the U.S.: A framework for teachers. Paper presented at the American Educational Research Association annual meeting, San Francisco, USA.

European Commission. (2011). Communication from the Commission to the European Parliament, the Council, the European Economic and Social Committee and the Committee of the Regions: Supporting Growth and Jobs: An Agenda for the Modernisation of Europe's Higher Education Systems, Available online: http://eur-lex.europa.eu/LexUriServ/LexUriServ. do?uri=COM:2011:0567:FIN:EN:PDF.

European Commission. (2013). Communication from the Commission to the European Parliament, the Council, the European Economic and Social Committee and the Committee of the Regions: European Higher Education in the World, Available online: http://ec.europa. eu/education/higher-education/doc/com499_en.pdf.

European Higher Education Area. (2012). Mobility for better learning: Mobility strategy 2020 for the European higher education area (EHEA), Available online: http://www.ehea.info/Uploads/ (1)/2012\%20EHEA\%20Mobility\%20Strategy.pdf.

European University Association. (2013). Internationalisation in European higher education: European policies, institutional strategies and EUA support, Belgium: European University Association. Available online: http://www.eua.be/Libraries/Publications_homepage_list/EUA_ International_Survey.sflb.ashx.

Government of Canada. (2012). International education: A key driver of Canada's future prosperity. Available online: http://www.international.gc.ca/education/assets/pdfs/ies_report_ rapport_sei-eng.pdf.

Green, M., Marmolejo, F., \& Egron-Polak, E. (2012). The internationalization of higher education: Future prospects. In D. D. Deardorff, H. de Wit, J. D. Heyl, \& T. Adams (Eds.), The SAGE handbook of international higher education (pp. 439-455). Thousand Oaks, CA: Sage Publications.

Hudzik, J. K. (2011). Comprehensive internationalization: From concept to action, Washington, DC: NAFSA. Available online: http://www.nafsa.org/uploadedFiles/NAFSA_Home/ Resource_Library_Assets/Publications_Library/2011_Comprehen_Internationalization.pdf.

International Association of Universities. (n.d.). Internationalization strategies advisory service, Available online: http://www.iau-aiu.net/content/isas.

International Association of Universities. (2010). Internationalization of higher education: Global trends regional perspectives - the IAU 3rd Global Survey Report. Paris: International Association of Universities. 
Knight, J. (1999). Internationalisation of higher education. In J. Knight \& H. de Wit (Eds.), Quality and Internationalisation in higher education. Paris: OECD/IMHE.

Knight, J. (2008). Higher education in turmoil: The changing world of internationalization. Rotterdam: Sense Publishers.

Leask, B. (2005, October) Internationalization of the curriculum and intercultural engagement: A variety of perspectives and possibilities. Paper presented at the Australian International Education Conference (AIEC), Queensland, Australia.

OECD. (2012). How many students study abroad and where do they go? In Education at a glance 2012: Highlights, OECD Publishing. Available online: http://dx.doi.org/10.1787/eag highlights-2012-9-en.

Otten, M. (2003). Intercultural learning and diversity in higher education. Journal of Studies in International Education, 7(1), 12-26.

Qiang, Z. (2013). Internationalization of higher education: towards a conceptual framework. Policy Futures in Education, 1(2), 248-270.

Report of the High-Level Group on International Education to the Tánaiste and Minister for Education and Skills. (2010). Investing in global relationships: Ireland's international education strategy 2010-2015. Available online: http://www.education.ie/en/Publications/Policy-Reports/ Ireland-s-International-Education-Strategy-2010-2015-Investing-in-Global-Relationships.pdf.

Rizvi, F. (2007). Teaching Global Interconnectivity, Paper presented at the Curriculum Corporation of Australia conference, Sydney Australia.

Spring, J. (2008). Globalization of education: An introduction. London: Routledge.

Teekens, H. (2003). The requirements to develop specific skills for teaching in an intercultural setting. Journal of Studies in International Education, 7(1), 108-119.

Teichler, U., Ferencs, I., \& Wächter, B. (2011). Mapping mobility in European higher education Vol. I., Brussels, European Commission.

UEFISCDI. (2013). The Status-Quo of Romanian National Policies on Internationalization of Education, Available online: http://pp-is.forhe.ro/sites/default/files/internationalization2.pdf. 